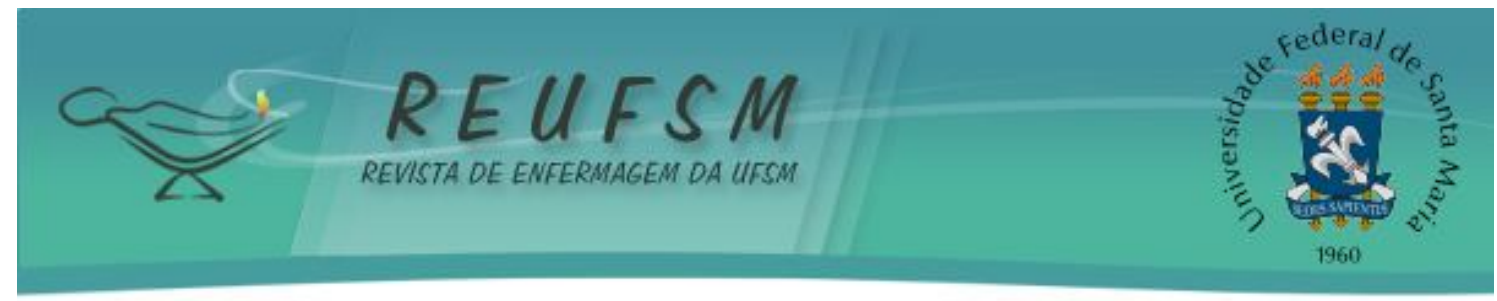

ARTIGO ORIGINAL

\title{
SENTIMENTOS DA FAMÍLIA DIANTE DO ENFRENTAMENTO DO VIVER-MORRER DO MEMBRO FAMILIAR NA UTI
}
FEELINGS OF FAMILY TOWARDS THE LIVING-DYING CONFRONTATION OF THE FAMILY MEMBER IN ICU

\section{SENT IMIENTOS DE LA FAMILIA DE LANTE DEL ENFRENT AMIENTO DE VIVIR Y MORRIR DEL MEMBRO FAMILIAR EN LA UCI}

\author{
Luzia Wilma Santana da Silva ${ }^{1}$ \\ Flávia Farias Santos ${ }^{2}$ \\ Deusélia Moreira de Souza ${ }^{3}$
}

\begin{abstract}
RESUMO: Identificar as principais necessidades das famílias que enfrentam situação de afastamento do familiar por necessidade de cuidados de alta complexidade; e conhecer a capacidade de resiliência das famílias durante a hospitalização de um dos seus membros em desvio de saúde numa UTI. Método: Pesquisa de natureza qualitativa, descritivoexploratória. Os sujeitos foram sete indivíduos de cinco famílias distintas, de ambos os sexos, que deram anuência em participar do estudo. Resultados: Algumas famílias descreveram sentimentos de esperança, fé e expectativa na recuperação do seu familiar. Conferem tais sentimentos à complexidade do ambiente intensivista, dotado de equipamentos tecnológicos, mas conferem a Deus a responsabilidade por trazer ao meio relacional-familiar o subsistema hospitalizado. Conclusões: Sensibilizar-se frente às necessidades dessas famílias requer do profissional, compaixão, entrega, aproximação ao sofrimento familiar, devendo o profissional de enfermagem conhecer a sua dor e sofrimento, revelando a essencialidade da existência humana envolta no processo de cuidar.
\end{abstract}

Descritores: Enfermagem; Família; Cuidados intensivos.

ABST RACT: To identify the main needs of families facing a situation of separation from the family member for high complexity care needs; and to know the resilience ability of families during the hospitalization phase of one of its members in health deviation in an ICU. Method: It was a qualitative research, with descriptive and exploratory nature. The subjects were seven individuals from five distinct families, of both sexes, who gave consent to participate on the study. Results: Some families described feelings of hope, faith and expectation in the recovery of their family member. They attribute such feelings to the complexity of the intensivist environment, equipped with technological apparatus, but give to God the responsibility of bringing to the relational-familiar environment the hospitalized subsystem. Conclusions: Raising awareness towards the

\footnotetext{
${ }^{1}$ Enfermeira. Doutora em Enfermagem - PEN/ UFSC. Professora Adjunta do Departamento de Saúde-DS/ UESB. Líder do Grupo Interdisciplinar em Ciências da Saúde e Sociedade. Linha: Família em seu Ciclo Vital e Política planjamento e gestão em Saúde. Docente do PPGES-Nível Mestrado. Coordenadora do NIEFAM/ UESB. Coordenadora do Laboratório de Enfermagem e da Disciplina Fundamentos do Processo de Cuidar em Enfermagem II. E-mail: Iuziawilma@gmail.com

2 Enfermeira. Graduada pela Universidade Estadual do Sudoeste da Bahia-UESB. Aluna Especial do Mestrado em Enfermagem do Programa de Pós-Graduação da Escola de Enfermagem da Universidade Federal da Bahia. Membro da Linha de Pesquisa: A família em seu ciclo vital. Colaboradora do Núcleo Interdisciplinar de Estudos e Extensão em cuidados às famílias em convibilidade com doenças crônicas/ UESB. Ex-monitora da Disciplina Fundamentos do Processo de Cuidar em Enfermagem II. E-mail: ffarias.santos@yahoo.com.br

3 Enfermeira. Mestre em Enfermagem-UFBA. Professora Assistente do Departamento de Saúde-DS/ UESB. Membro dos Grupos de Pesquisa: GREPE e EXERCE. Docente da Disciplina Fundamentos do Processo de Cuidar em Enfermagem II. E-mail: deusams@gmail.com
} 


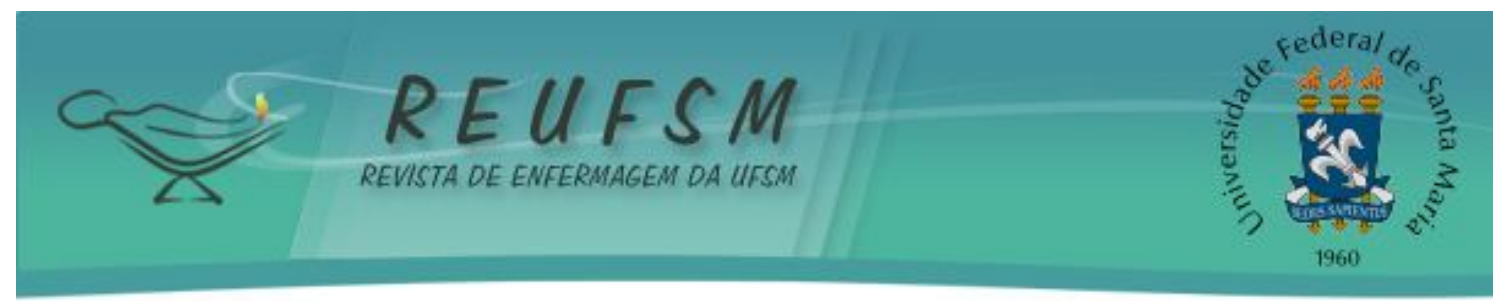

needs of these families requires from the professional, compassion, delivery, approximation to the family suffering, nursing staff should know their pain and suffering, revealing the essence of human existence wrapped in the care process.

Descriptors: Nursing; Family; Intensive care.

RESUMEN: Identificar las principales necesidades de las familias que enfrentan situación de separación del familiar por necesidad de cuidados de alta complejidad; y conocer la capacidad de resiliencia de las familias durante la fase de hospitalización de uno de sus miembros en desvío de salud en una UCl. Método: Investigación cualitativa, con carácter descriptivo y exploratorio. Los sujetos fueron siete personas de cinco familias distintas, de ambos sexos, que dieron su consentimiento para participar en el estudio. Resultados: Algunas familias describieron sentimientos de esperanza, confianza y expectativa en la recuperación de su familiar. Atribuyen estos sentimientos a la complejidad del ambiente intensivista, equipado con aparatos tecnológicos, pero confían a Dios la responsabilidad de traer al medio ambiente relacional familiar el subsistema en hospitalización. Conclusiones: Sensibilizarse frente a las necesidades de estas familias requiere del profesional, la compasión, la entrega, la aproximación al sufrimiento de la familia, el profesional de enfermería debe saber su dolor y sufrimiento, revelando la esencia de la existencia humana envuelta en el proceso de cuidar.

Descriptores: Enfermería; Familia; Cuidados intensivos.

\section{INTRODUÇÃO}

A inesperada e abrupta hospitalização em Unidade de Terapia Intensiva (UTI) de um membro familiar pode desencadear estresse, tensão, medo da morte e desesperança nos demais subsistemas familiares, situação que afeta o processo de viver humano da família em sua globalidade.

Os sentimentos referidos anteriormente ecoam em estudos sobre esta temática e apontam à necessidade de um olhar mais atento sobre os sentimentos da família em situação de enfrentamento do viver-morrer de um dos seus membros numa UTI.

A compreensão/ percepção sobre a UTI envolve o imaginário popular na crença de que este ambiente desvela duas situações extremas e ao mesmo tempo proximais - o morrer e o viver -, podendo acarretar situações de desorganização nas relações familiares, contribuindo para que a família, envolvida pela tensão e medo, torne-se inapta a desenvolver sua capacidade de resiliência, ou seja, de recuperação e manutenção do comportamento adaptativo protetor diante da ameaçada de eventos estressores, em um momento que exige 0 'equilíbrio' físico e emocional, contributivos para a atuação juntamente à equipe de saúde na assistência ao paciente - familiar - em terapia intensiva. Do mesmo modo, a notícia de hospitalização faz emergir no subsistema familiar uma sensação de estranheza e impotência, repleta de medos e ansiedades ocasionados pelo processo de internação. ${ }^{1}$

Nessa concepção, compreender que o indivíduo internado em UTI não representa um corpo em situação de desvio de saúde, mas revela um ser existencial, devendo o olhar sobre este perscrutar o cuidar para além de uma visão biologicista, que possa alcançar sua multidimensionalidade e necessidade inter-relacional com seus pares familiares.

Neste contexto, entende-se que cuidar do paciente hospitalizado implica em prestar assistência concomitante a sua família, a qual necessita de apoio emocional para manter-se forte e segura, apta a enfrentar a situação de distanciamento de um dos seus membros, encorajado-a a se reestruturar, a fim de que possa servir de suporte ao paciente hospitalizado. ${ }^{2}$

Desta compreensão, o presente estudo teve como objetivos: identificar as principais necessidades das famílias que enfrentam uma situação de afastamento do familiar por precisão de cuidados de alta complexidade, e conhecer se essas famílias 


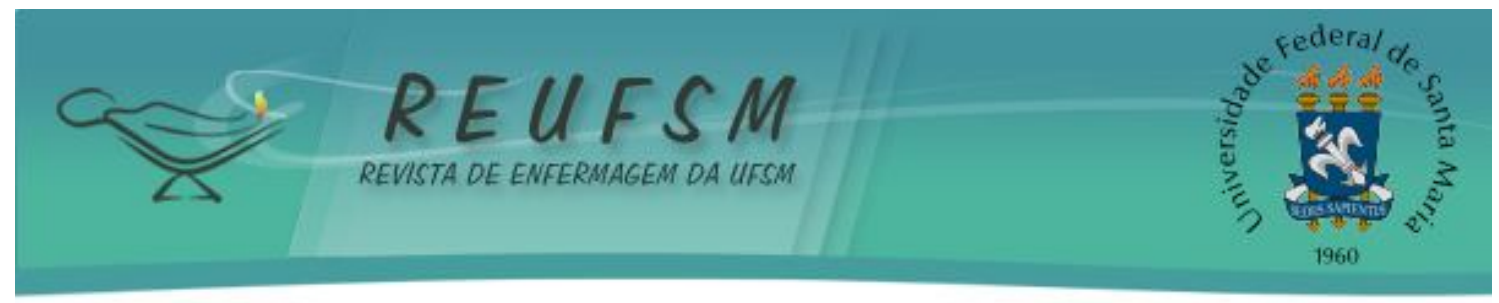

desenvolvem capacidade de resiliência durante a fase de hospitalização de um dos seus membros em hospitalização na UTI.

Acreditamos que estudos desta natureza possam disponibilizar mais conhecimento sobre os sentimentos vivenciados pelas famílias de pacientes internados em UTI. Tal crença assenta-se na escassez de estudos sobre a temática em bases de dados. Ainda porque vislumbramos o paciente como parte, um subsistema da família, e as inter-relações estabelecidas neste sistema afeta diretamente uns aos outros. ${ }^{3}$

\section{MÉTODO}

Trata-se de um estudo de abordagem qualitativa, que se caracteriza como descritivo-exploratório. Teve como cenário de pesquisa a UTI adulto do Hospital Geral Prado Valadares - HGPV -, hospital de referência regional, do interior da Bahia, localizado na cidade de J equié.

Os sujeitos deste estudo foram sete indivíduos de cinco famílias distintas, de ambos os sexos, entre 18 e 43 anos, identificados com nomes fictícios, escolhidos pelos próprios sujeitos, que deram anuência em participar do estudo e atenderam aos critérios de inclusão: a) ser familiar do paciente internado na UTI sem necessariamente, de consanguinidade; b) ter vínculo relacional proximal com o familiar internado na UTI; c) ser familiar com maior frequência no ambiente hospitalar em visita/acompanhamento do paciente internado na UTI; e d) serem alfabetizados.

A coleta dos dados constituiu-se de três instrumentos: entrevista semiestruturada aos familiares acompanhantes do paciente na UTI, carta escrita pelo familiar e direcionada à coordenação de enfermagem da UTI; Ecomapa adaptado para identificar a rede de relação e suporte familiar como apoio às necessidades biopsicossociais afetadas da família pelo enfrentamento em ter o membro familiar internado na UTI, e diário de campo.

A entrevista semiestruturada consistiu num roteiro de questões norteadoras que serviu para dar apoio às pesquisadoras na coleta de dados. A carta consistiu num instrumento de expressão não verbal, um registro que seguiu a regra gramatical vigente da Língua Portuguesa. O Ecomapa, um diagrama que permitiu identificar a rede de relação vincular mais extensa do familiar, sendo adaptado para a rede vincular proximal das pessoas em enfrentamento da hospitalização do membro familiar na UTI. Buscou-se, assim, conhecer o suporte que estes membros recebem da unidade hospitalar e da sua família, durante a hospitalização do familiar na UTI. O diário de campo foi utilizado para registro das observações, impressões e percepções do campo pelas pesquisadoras, visando a constituir-se em subsídio para análise dos dados.

O Estudo foi aprovado pelo Comitê de Ética em Pesquisa, da Universidade Estadual do Sudoeste da Bahia, Protocolo n 223/ 2009, em respeito à Resolução 196/ 96 do Conselho Nacional de Saúde.

No que se refere ao tratamento e análise dos dados, desvelá-los se fez a partir do modelo interativo sugerido por Miles e Huberman, com a técnica de análise de conteúdo, que consistiu num processo de idas e vindas, iniciado desde a definição do problema de estudo, prosseguindo até 0 alcance do relatório final. ${ }^{4}$

Neste processo de redução e redução na transversalidade dos instrumentos de coleta de dados, alcançaram-se três categorias e sete subcategorias. Essas foram se constituindo, a partir das falas dos sujeitos, em três momentos. No primeiro, as falas foram agrupadas conforme suas semelhanças de sentido. No segundo, a análise e agrupamento das falas foram definidas segundo a sua atração dimensional, e por fim, no terceiro momento, configurou-se na definição de categorias e subcategorias com os seus respectivos códigos. Tratou-se, portanto, de um processo criterioso, laborioso e de grande desvelamento dos dados. 


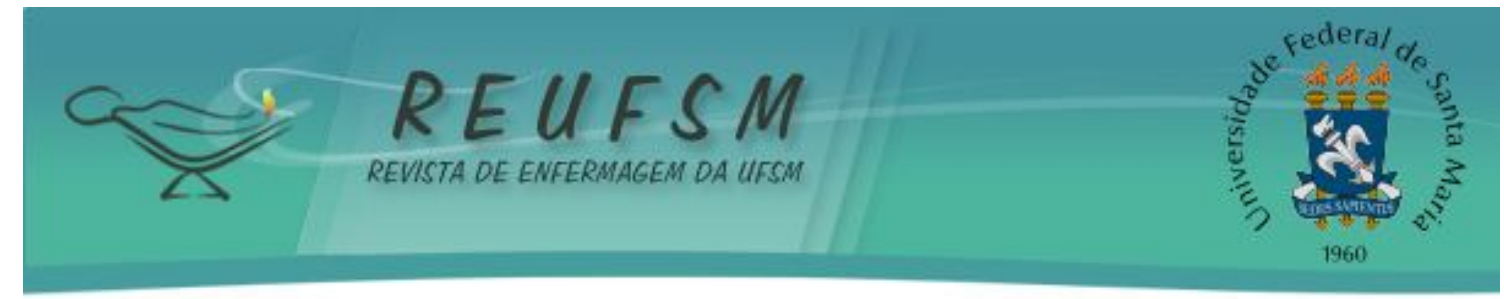

RESULTADOS E DISCUSSÕES

Os resultados seguem apresentados e discutidos segundo as categorias que emergiram a luz dos discursos dos sujeitos que compuseram este estudo.

"O ambiente da UTI - percepções familiares frente ao enfrentamento de seus subsistemas" surge como uma categoria na qual a família expõe suas percepções e apreensões ao ambiente da UTI.

No primeiro momento em que recebem o impacto da notícia de hospitalização do membro familiar na UTI, a família vivencia tristeza, medo e insegurança; sentimentos relacionados à falta de conhecimento do ambiente e de sua dinâmica de funcionamento. Formam um conceito prévio da unidade intensiva ${ }^{5}$, vislumbrando-a como o local destinado à internação de pacientes com poucas chances de sobrevivência, e assim, relatam:

No momento em que eu soube fiquei muito triste, porque a primeira impressão que eu tive é que a pessoa ia chegar a óbito, acho que [...] eu tenho essa impressão, assim, tinha, agora eu tenho outra visão que eu acho assim, numa primeira impressão foi que eu falei assim, se vai para UTI não volta mais, mas através de eu ver e das explicações do médico não é isso. (Família 1 Girassol - irmã)

Ah! Medo, quando eu entrei logo eu senti medo, mas é mais seguro (pausa na voz), acho mais seguro para os pacientes, tem todos os equipamentos (pausa na voz), dá medo quando entra logo a primeira vez, mas eu acho ele seguro para os pacientes [...] acho que ai é o melhor lugar pra ele tá, o lugar mais seguro. (Família 2 Rosa Vermelha - Esposa)

Por outro lado, após vivenciar e conhecer a unidade de cuidados intensivos os familiares são capazes de reconhecer e identificar a importância deste ambiente para a recuperação do membro familiar em desvio de saúde ${ }^{6}$, e assim, passam a vislumbrar a UTI como o local melhor preparado para receber, assistir e permitir a sobrevivência de pacientes criticamente enfermos.

[...] ela tá num lugar onde tá todo o aparato médico para tirar 0 paciente da situação crítica [...] é o ambiente apropriado para pacientes de situações gravíssimas. A aparelhagem que tem dentro desta sala aí é extremamente essencial para tirar um ser humano de uma situação difícil, seja ele um local de oxigênio ou uma medicação mais complexa, um tratamento mais complexo. (Família 5 Copo de leite - Primo)

A aceitação da UTI como ambiente propício para pacientes gravemente enfermos devese ao posterior conhecimento adquirido após adentrar e vivenciar a dinâmica da unidade; e, perceber que a complexidade que envolve o ambiente se faz necessária à continuidade da vida.

Por tanto, aspectos como a frieza do ambiente, pela climatização, relacionada à necessidade de conservação da aparelhagem e controle de infecções; 0 uso de equipamentos de alta tecnologia para suporte à vida; o rigoroso e diminuto horário de visitas; a especialização dos profissionais caracterizam a preocupação em oferecer aos pacientes em estado crítico uma assistência de suporte à vida, que envolve a manutenção dos sistemas vitais e a busca pela homeostase, de modo a garantir alta da UTI e não entregar o corpo morto à família, visto que trata-se de um ambiente pensado para os casos 


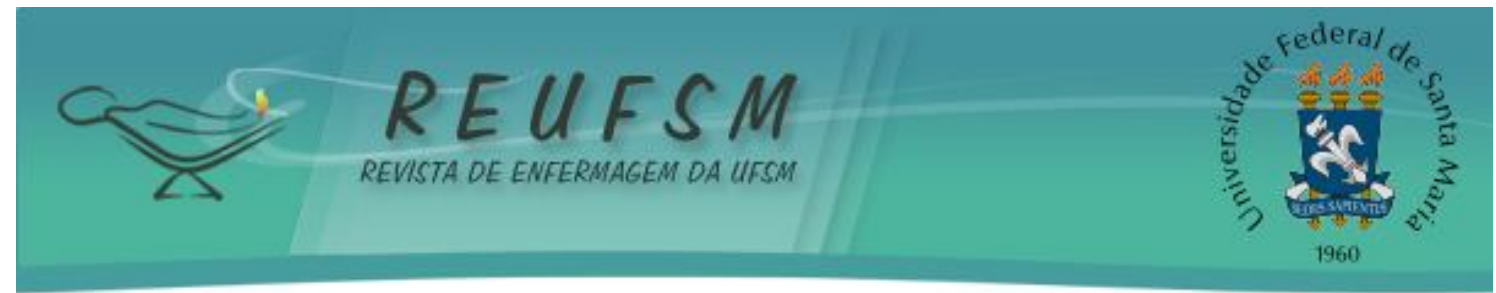

em que há esperança de vida. E, assim, quando a família toma ciência de que há a possibilidade de que seu ente familiar saia deste ambiente recuperado, ela tem sua esperança aumentada em ter seu familiar de volta em seu meio vivencial relacional.

Nesse momento, é fundamental 0 apoio que os familiares recebem dos profissionais de saúde, os quais jamais devem perder de vista a importância de direcionar seus ol hares para além do cuidado ao enfermo, alcançando a assistência a sua família. Sabe-se, no entanto, que a complexidade envolta na unidade de cuidados intensivos gera tensão nos profissionais, e isso pode acabar dificultando a aproximação deste com 0 familiar, a comunicação, a assistência voltada às necessidades da família.

Porém, foi possível perceber, nos discursos dos sujeitos do estudo, que em suas experiências, durante o enfrentamento da hospitalização do familiar na UTI, puderam contar com o apoio de profissionais que tiveram sensibilidade de reconhecer o difícil e doloroso enfrentamento que vivenciavam.

[...] a gente encontrou assim, em primeiro lugar, uma psicóloga, uma pessoa maravilhosa que tá dando uma maior atenção, todo dia ela incentiva cada vez mais. O médico também, que ele dá, quando ele passa o boletim médico, ele fala tudo, esclarece, deixa tudo bem esclarecido [... ] então foi isso, uma pessoa aqui pra orientar, a gente precisava de uma orientação [...] (Família 1 Girassol - irmã) [...] eles pedem até que a gente converse com o paciente, mesmo ele estando inconsciente, que é o caso do meu irmão - “não, converse com ele, pode falar, mesmo que ele não responda, mas ele vai perceber que você está aqui. (Família 2 Violeta - Irmã)

Sensibilizar-se frente às necessidades dessas famílias requer do profissional compaixão, entrega, aproximação ao sofrimento do outro. Implica, então, em colocar-se no lugar do outro, conhecer sua dor e sofrimento, tornando possível uma assistência singular. ${ }^{7}$

É importante ressaltar que a credibilidade dada pela família aos profissionais de saúde contribui para amenização da ansiedade, tensão e medo, pois passam a confiar na equipe e nutrir mais esperança na recuperação de saúde do membro familiar.

[...] a gente também acredita que aqui, todo profissional tá sendo muito assim competente e tá trabalhando com amor pelo que a gente percebe, que não é só a questão da técnica, é também a questão da afetividade, a gente tem percebido isso nos profissionais aí dentro, então isso também conforta a gente [...] conforta o fato de saber que existem bons profissionais aí dentro [...] dá uma segurança maior. (Família 2 Violeta - Irmã)

[...] a gente não pode fazer nada no momento, tem que confiar nos médicos [...] a gente não pode entrar em desespero e nem pode maltratar os médicos, enquanto tiver cuidando da gente também com carinho, porque a gente precisa de carinho deles também, né isso? Precisa de um bom atendimento [...] porque a gente não tem conhecimento do que tá acontecendo aqui dentro, só eles têm [...]. (Família 3 Margarida - Mãe)

Percebe-se, assim, que o reconhecimento por parte dos familiares, da atenção pelos profissionais de saúde, deve-se, na maioria das situações, a atitudes simples, como olhar nos olhos, direcionar palavras de conforto, amenizar a dor com informações do familiar enfermo, e 


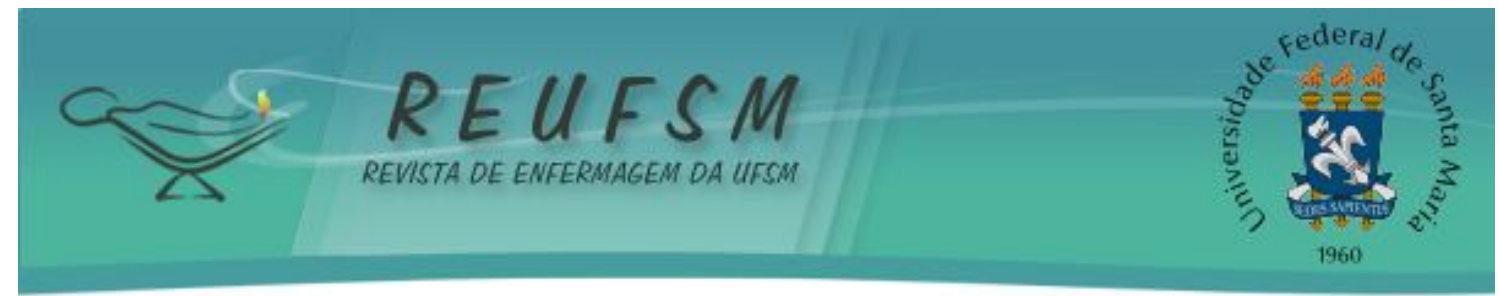

mostrar a família que ele estará lá, em seu exercício profissional pela vida ou pela dignidade da morte, e assim, ajudar a viver a experiência de responder à doença mais fortalecida. ${ }^{8}$

Tal fortalecimento ancora-se no princípio da necessidade humana de segurança. Segurança é um princípio regulador que permite ao ser humano adaptar-se às dificuldades e encontrar formas para conduzir a vida diante das adversidades ${ }^{9}$, que, neste caso, é o enfrentamento da UTI.

Paralelos a essa situação, se deparam com um serviço, a UTI, um local com horários rígidos para visitas, por vezes inflexíveis, diminutas em tempo de permanência neste espaço ao lado do familiar. Tais características afloram por necessidades de proximidade do ente querido hospitalizado na UTI. Sobre isto, autores ${ }^{10}$ referem que 0 curto tempo de visita e o número restrito de visitantes por doente conferem à família a sensação de impossibilidade, razão pela qual buscam satisfazer esta necessidade na espiritualidade, como força para suportar as adversidades.

Para as famílias deste estudo, a visita representava um momento de renovação da fé, um momento de interação, de valorização da família em sua globalidade, pois se tornavam mais unidos, conforme enunciaram:

[...] a necessidade que a gente tem assim é de ver mais a pessoa, mas UTI é UTI, né? Tem um limite de visitas, e aí a gente vê pouco, o tempo é pouco. Então, como é parente, irmão, a gente quer ver sempre para ver se tá bom, como é que tá. (Família 4 Lírio - Irmão) [...] o que a gente tá necessitando no momento é de visitar nosso ente querido, nós sabemos que, por direção do hospital, só é permitida a entrada de duas pessoas pela manhã e duas pela tarde, como a família da gente é grande, a gente fica um pouco assim, a gente acha que o hospital tá deixando a desejar [...]. (Família 5 Copo de leite - Primo)

Porém, apesar desta necessidade, o conforto familiar pode ser alcançado por meio das visitas diárias - o ver/perceber a melhora do quadro clínico ou não -, assim, a amenização da sua dor e aumento da esperança, ou também, o avesso da situação. Contudo, por reverter-se num período curto - a visita -, faz com que as famílias vivenciem sentimentos de medo, apreensão, insegurança, tristeza e temor da morte.

No entanto, a família também compreende a necessidade de ter seu horário de visita restrito, passando a aceitar, não em sua totalidade, mas como forma de evitar complicações ao quadro clínico do ente querido, assentada no que percebe como complexidade do tratamento na UTI. Por outro lado, se vê em estado de fragilidade e em risco também de adoecimento, pela sobrecarga de tensão emocional que vivencia neste momento da sua vida. Assim, dizem também necessitar serem cuidadas.

A tensão emocional é ainda mais intensificada pela expectativa do boletim médico fazendo com que as famílias vivenciem momentos de medo, "o chão que foge aos pés", sobre 0 que virá a ser anunciado do quadro clínico. A família expressa, paralelo a essas sensações, o temor de que as informações não correspondam às suas expectativas de melhora do familiar.

[...] fico muito pensativa de ele me dar uma resposta assim negativa, como, no caso, ela não vai resistir, pra eu fortalecer a família que o tratamento dela não tá dando certo, a dificuldade mais pra mim é essa [...] difícil é o momento que eu vou embora, eu fico com medo de chegar no outro dia e não encontrar ela mais com vida [...] (Família 1 Girassol - irmã) 


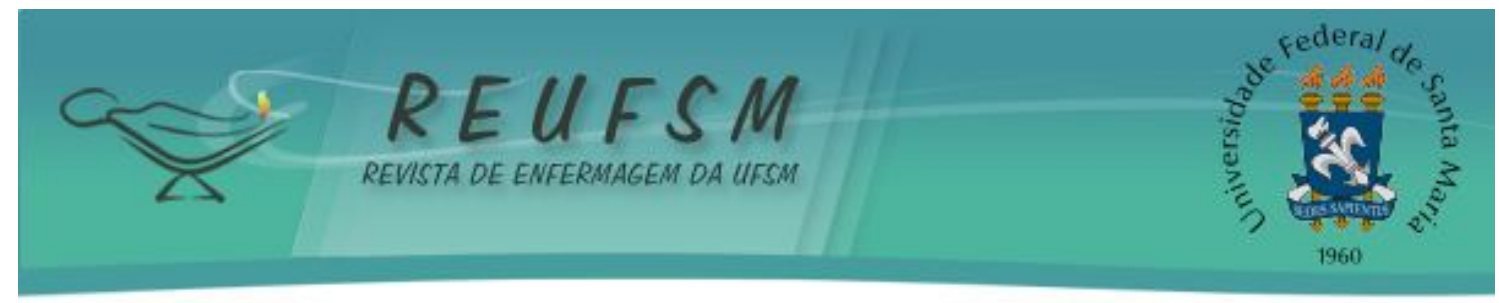

[...] nesse momento tou sentindo mais necessidade que o laudo chegue mais rápido, porque o laudo tá lá na Sonimed e eu quero resposta, porque o médico me falou que só me dá resposta quando o laudo vim da Sonimed [...] (Família 3 Margarida - Mãe)

Neste contexto, a família solicita por ser orientada, quantas vezes forem necessárias para que compreenda a situação na qual se encontra seu familiar, sobre todos os aspectos que envolvem a hospitalização na UTI, e que neste momento, o profissional não deve restringir as informações à mera comunicação superficial, pois assim a deixará mais susceptível a adquirir problemas de saúde pela ansiedade, tensão, medo do desconhecido, o que avulta sua apreensão.

Essa categoria demonstrou que quando recebem o apoio e assistência da equipe de saúde, os familiares sentem-se mais seguros para vivenciar o enfrentamento, e mais confiantes na recuperação do ente querido, passam a conhecer melhor o ambiente da UTI, a perceber este espaço de cuidados como o mais preparado a receber seu familiar doente, e, assim, proporcioná-lo melhores condições de sobrevivência.

A categoria "Fé e esperança: sentimentos confortadores da família" ampliou a anterior, quanto ao enunciado medo, tristeza, apreensão, ao tempo em que evidenciou fé, esperança e espiritualidade como fenômenos antagonistas e fortalecedores à família.

Ao se deparar com a 'aguda' e inesperada hospitalização do membro familiar em UTI, a família vivencia um grande impacto na sua estrutura, desencadeador de intensas emoções de dor.

Muito triste, não sei nem explicar direito. Trás uma angústia, medo, insegurança, tudo isso, tudo junto [...] Ah eu fico angustiada, eu queria ficar aqui o tempo todo, mas não pode [...]. (Família 2 Rosa Vermelha - Esposa)

É triste, é angustiante, dá medo de muitas (pausa na voz), de perdêlo, de acontecer alguma coisa com ele, sendo que eu não posso fazer nada [...] Angústia, aflição [... . (Família 2 Girassol 2 - Filho)

Eu sinto muita dificuldade de dormir, de comer, de assistir, de tudo (pausa na voz), eu chego em casa, deito e às vezes não me alimento, não durmo. (Família 2 Rosa Vermelha - Esposa)

Diante do enfrentamento, as famílias referem à necessidade de alguém manter-se forte para amparar os demais membros. A compreensão que envolve essa premissa está na história familiar, referida por estudiosos de família, em que há a pessoa índice, como a fortaleza da família para onde todos os 'canais drenam', alimentando 'o grande oceano', ou seja, o sistema relacional-vivencial familiar.

A pessoa índice é então o 'oceano', e como afirmam autores ${ }^{11-12}$, aquela na qual se centram a gênese familiar de moral e ética, cujo papel de protetora, acolhedora, educadora, dentre outras funções, mantém as pessoas pelos vínculos relacionais recursivos de respeito, amor, gratidão, cooperação, entre outros sentimentos positivos.

Nas famílias, este suporte emocional adveio dos mais diversos membros, em maior intensidade daqueles mais proximais.

[...] converso com minha filha (pausa na voz), tento fazer alguma coisa assim que me acalme. (Família 2 Rosa Vermelha - Esposa)

[...] às vezes, quando um começa a chorar, o outro vai e dá conselho, dá apoio, nós faz assim [...] nós só é quatro, eu e ele, a menina e o pai, né? Então, nós vai sentar junto e conversar [...]. (Família 3 Margarida - Mãe) 


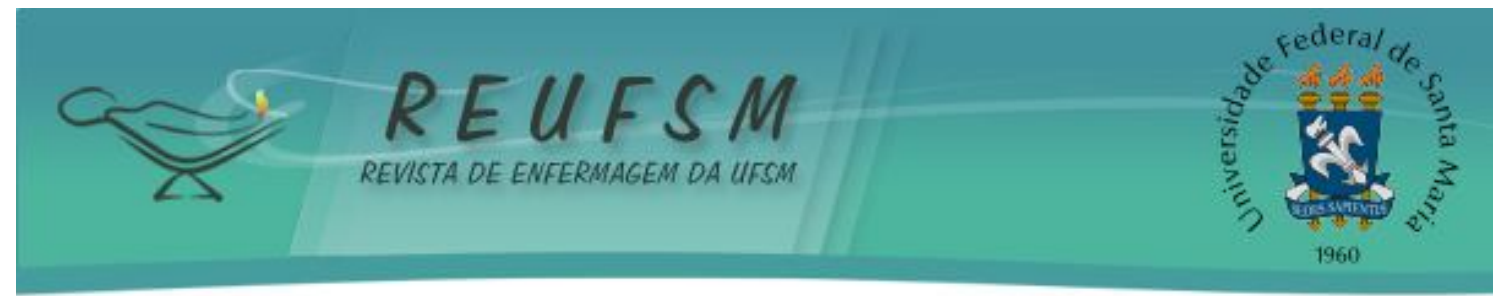

Neste contexto, compreende-se que em meio à complexidade da UTI, aparelhagens e técnicas, faz-se necessário perceber a família que ali se encontra, que também sofre, padece e se desestrutura frente a possibilidade de perda de quem se ama, e assim, necessita de um olhar mais sensível da equipe de saúde, capaz de percebê-la, no silêncio das palavras, nos gestos, no olhar triste e desconsolado de sua dor, da angústia, do medo, da insegurança, e neste momento, usar da intersubjetividade para colocar-se no lugar do outro, transcendendo o cuidar para a essencialidade do cuidar, visando à satisfação das necessidades afetadas das famílias na antessala da UTI.

A espiritualidade surge como uma forma de superação, plano no qual as famílias buscam se fortalecer, e, está relacionada à individualidade de cada ser humano, constituída pelos pensamentos, emoções e relacionamentos interpessoais, vinculada ao existir da pessoa que transcende a si mesma em busca do sentido da vida. ${ }^{13}$ Sentido este, que, por momentos, encontra-se a procura por definição pela vivência da hospitalização na UTI de quem se ama. Assim, a família se une ou se desarranja diante de sentimentos desconfortantes, que a faz buscar o sentido da vida.

[...] alguém da família, um familiar, a gente tem que superar tudo, o importante é a superação a cada dia que passa ter fé em Deus [...] fazendo muitas orações [...] muita fé em Deus [...] Tem Deus acima de tudo, que Ele é o Pai de todos nós e Ele passa aquela força no momento da oração todo dia, todos os dias tem oração [...] (Família 1 Girassol - irmã)

Senta e conversa um com o outro, e assim, tem que ter paciência, tem que ter calma, um dá conselho o outro e pede muita força a Deus, que Deus acalme a gente, que Deus é bom, poderoso e que dá força a ele e ol ha ele cada momento [...] a gente só quer o melhor chegue pra ele, mas tá nas mãos dos médicos e nas mãos de Deus, né? (Família 3 Margarida - Mãe)

As famílias agarram-se no Ser supremo, aquele capaz de Ihes trazer conforto e calma ao coração, e, sobretudo, a recuperação daquele que se encontra no ambiente da UTI. A família parece entregar a Deus a responsabilidade pela vida do familiar, e o faz por meio de orações e canções de louvor, conversas com Deus pela recuperação da pessoa amada pela família.

Compreender esses aspectos implica em aceitar que a presença no divino está relacionada à cura, como enunciam nas falas:

[...] mas eu peço força a Deus no momento que eu saio [...] faço uma oração perto dela, peço a Deus, toco na cabeça dela e peço a Ele pra proteger muito [...] peço muita força a Deus para no próximo dia seguinte eu chegar encontrar ela cada vez melhor. (Família 1 Girassol - irmã)

A gente sabe que UTI é viver ou morrer, então, a gente espera que ela vá viver e com certeza ela vai viver [...] o conforto da gente, como acredito, na maioria das pessoas, é Deus, a gente acredita que vai dar certo e com certeza vai dar certo [...] saber que a pessoa ta na UTI ali, é tristeza mesmo e esperança ao mesmo tempo. (Família 4 Lírio - Irmão)

Essas falas chamam palavras que encontram na sua raiz a supremacia de um ser superior - Deus -, aquele onipotente. Assim, a Ele cabe o poder de decidir entre a vida e 


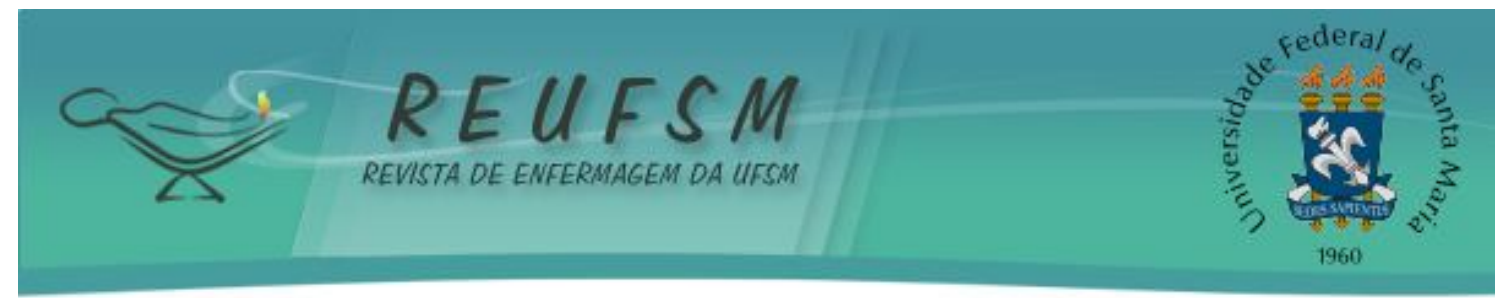

a morte. No entanto, o desejo humano das famílias pede para que seja feita a sua vontade, ou seja, a vontade dela. Em outras palavras, que seja concedida a recuperação e o retorno do membro familiar ao convívio no meio relacional-vivencial familiar.

Aqui rege, então, a necessidade de satisfazer a espiritualidade no sentido de que ela seja atendida, de modo que se possa alcançar o ápice das necessidades humanas básicas. No entanto, como dizem os autores ${ }^{149-15}$, a espiritual idade é uma necessidade que está sempre por ser satisfeita. Assim, é reforçada cotidianamente, pois se mantém como essencial à existência humana.

Considerar este aspecto mostra-se como ponto sine qua non do cuidado profissional, neste estudo, ao olhar para os profissionais de enfermagem. Assim, é importante valorizar os sentimentos da família, tendo em vista buscar fortalecê-las, a partir da identificação de suas necessidades básicas individuais/coletivas, de modo a ajudá-la na promoção de sua saúde físico-emocional para que esteja apta a cuidar do ente familiar quando da alta da UTI.

A categoria A rede social de apoio a família - construção na antessala de espera da UTI - permitiu a reflexão acerca da importância da rede social de apoio, estabelecida na antessala da UTI, às famílias sob o enfrentamento do desvio de saúde do membro familiar, no que tange ao desenvolvimento da resiliência frente à adversidade que se apresentava, e, assim, manutenção do 'equilíbrio' no enfrentamento da hospitalização.

A rede social aproxima de forma positiva as pessoas em relações de vínculos de amor, respeito, solidariedade, solicitude e apoio nas necessidades inerentes à manutenção do 'equilíbrio' enquanto necessidade humana básica. ${ }^{16}$

$\mathrm{Na}$ antessala da UTI, na espera pelo horário de visitas, as famílias passavam a conviver e ali trocar experiências uma com as outras, que também vivenciam a hospitalização de um ente familiar. Partilhavam sofrimento, solidariedade, vínculos de amigos e parentes, construindo uma teia fraternal de apoio.

[...] quando a gente senta aqui com as visitas dos outros pacientes, a gente conversa muito, então a gente procura sempre se apoiar um no outro, eu acho que, às vezes, o pessoal aí dentro nem sabe, mas é muito importante o contato que nós temos um com o outro aqui fora, a gente adquire amizade, um busca café para o outro, o outro busca (pausa na voz) eh, oferece uma carona, oferece um alojamento, entendeu? (Família 2 Viol eta - Irmã)

$A h ! O$ apoio que a gente recebe das pessoas que vem aqui visitar 0 parente. Aqui todo mundo ajuda um e outro. A gente conversa, faz amizade e isso conforta, sabe como é? É como se fosse família, sabe? Ajuda a gente, ajuda muito, me dá mais força pra melhorar essa dor. (Copo de leite Família 5 - Primo)

Tal situação é facilmente compreendida quando se conhece a fragilidade que as famílias se encontram neste momento da vida, necessitando de algo que lhes sustente, que Ihes dê condições de enfrentar a situação fortalecendo-as. Neste momento, uma compreende a situação da outra e juntas buscam ajuda mútua em gestos simples, pela facilidade de desenvolvê-los, mas grandiosos pela sua essência, a exemplo, buscar um café, oferecer um copo d'água, oferecer sua casa para descanso, trazer alimentos, dar carona. Atos em que as famílias vão tecendo em fios sua rede de apoio, construindo os nós de amizade, de maneira que, nesse caminhar, vão se amparando e encontrando forças para vivenciarem o momento de experiência da UTI.

Assim, o ambiente perturbador da UTI faz emergir sentimentos afetivo-proximais que configuram uma nova família, à luz da nossa compreensão - família vincular por laços de amizade constituída temporariamente por pessoas que jamais se viram, e, num momento inesperado da 


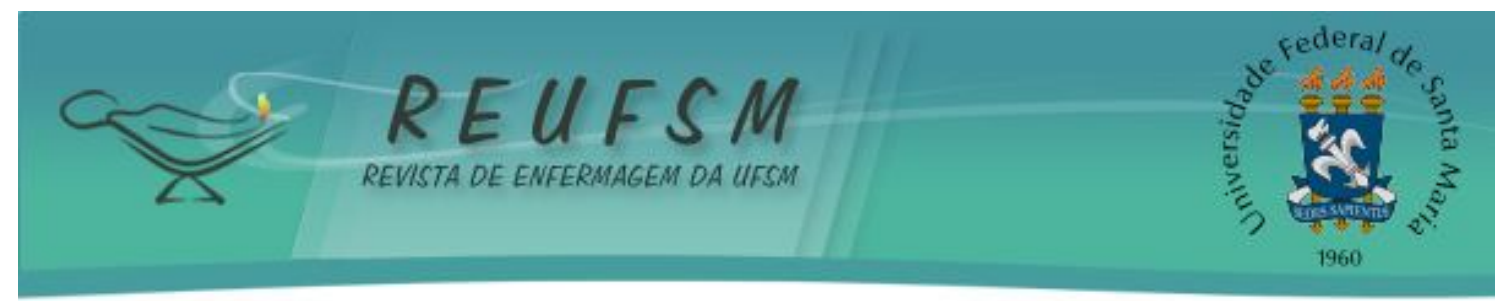

vida, se encontram, se conhecem, compartilham experiências e sentimentos, e, juntas, apóiam-se para alívio da dor, angústia, apreensão sobre o medo da perda de quem se ama. E assim, estabelecem um vínculo que pode perdurar por tempos - família da antessala da UTI.

\section{CONSIDERAÇÕES FINAIS}

As necessidades psicobiológicas e psicossociais das famílias mostraram-se enoveladas ao seu processo de viver, sendo expressas em sentimentos, sensações, e simbolismos aos enfrentamentos do viver morrer do ente familiar na UTI.

As famílias expressam também a necessidade de serem percebidas-cuidadas pelos profissionais; diziam que atitudes simples, como 'olhar nos olhos', dizer uma só palavra que acalmasse suas inquietações, já representariam atos de cuidado. Assim, proporcionar-lhes-ia mais conforto na antessala da UTI.

Por outro lado, as famílias se constituíam em apoio umas as outras, ancorando-se na espiritualidade, na fé e na esperança para o alívio das suas angústias, medos e sofrimentos. Compartilhavam experiências e emoções aos desconfortos psicobiológicos.

Percebe-se que direcionar atenção aos sentimentos dessas famílias surge como uma necessidade de um cuidado especial, que envolve zelo, desvelo, atitude e solidariedade, como práxis do cuidado profissional, ou seja, olhar para a multidimensionalidade humana, afastando-se do modelo biomédico e estabelecendo o foco de cuidados em suas multirrelações existenciais. ${ }^{17-18}$

A busca pela promoção da saúde integral às famílias no ambiente hospitalar ainda não é uma realidade. Para tal, fazem-se necessárias ações de Políticas Públicas de Saúde que atendam a essa demanda, que se avulta dia a dia no cenário nacional, visto o desenvolvimento tecnológico em saúde e as possibilidades de atendimento de alta complexidade que se mostra na atualidade, demandando assim novos direcionamentos político-profissionais que possam contemplar o ser familiar como suj eito de cuidado no ambiente hospitalar ${ }^{19}$. Pois, quem cuida também precisa ser cuidado, fato enunciado pela ampla literatura nacional e internacional, tendo em vista a promoção da saúde das pessoas.

Compreende-se, ainda, que se faz necessário a formação de profissionais de saúde sensíveis e capazes de redesenhar o contexto de sua ação cuidativa, frente às experiências e sentimentos de outras pessoas para além do paciente no alcance aos familiares de pacientes. Assim, percebê-los como suj eitos também de sua práxis, especialmente, quando do enfrentamento do viver morrer de um de seus membros em UTI, de modo a perceber sua necessidade de apoio, e assim, tornasse "mola propulsora" para o desenvolvimento da capacidade de resiliência familiar na superação dos agentes estresses oriundos dos sentimentos do medo da perda do ente familiar na UTI.

\section{REFERÊNCIAS}

1. Pinho LB de, Kantorski LP. Refletindo sobre o contexto psicossocial de famílias de pacientes internados na unidade de emergência. Cienc enferm. 2004; X(1):67-77.

2. Silva LWS da. A dinâmica das relações da família com o membro idoso portador de diabetes Mellitus tipo2. Florianópolis: [s.n.], 2007.311p. Tese (Doutorado):- Universidade Federal de Santa Catarina, 2007.

3. Bertalanffy LV. Teoria Geral dos Sistemas; $3^{\circ}$ ed. Petrópolis: Vozes; 1977. 351 p.

4. Miles MB, Huberman M. Drawing valid meaning from qualitative data: toward a shared craft, in Educational researcher, 1984.

5. Martins JJ, Nascimento EP, Geremias CK, Schneider DG, Schweitzer G; Neto HM. O acolhimento à família na unidade de terapia intensiva: conhecimento de uma equipe multiprofissional. 


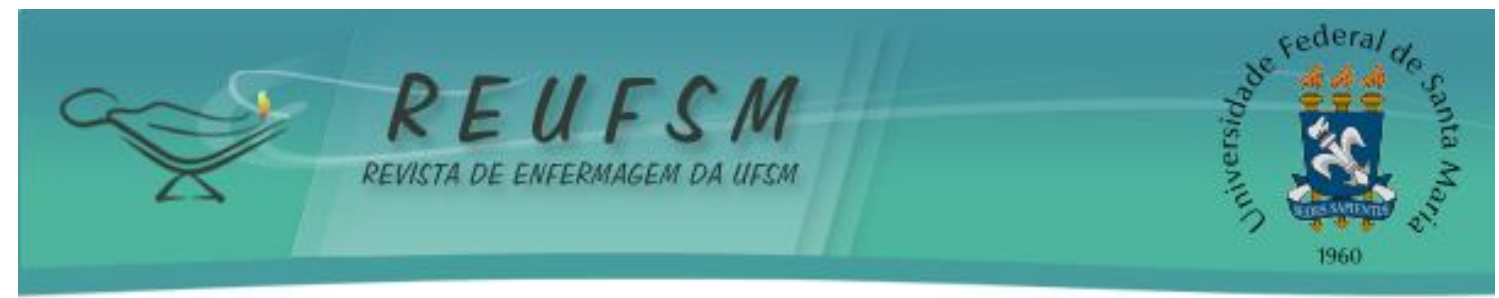

Rev eletrrônica enferm [periódico na internet]. 2008 [acesso em: 28 de nov. de 2009];10(4):1091-101. Disponível em: http:// www. fen. ufg. br/ revista/ v10/ n4/ pdf/ v10n4a22. pdf.

6. Lemos RCA, Rossi LA. O significado cultural atribuído ao centro de terapia intensiva por clientes e seus familiares: um elo entre a beira do abismo e a liberdade. Rev latinoam enferm. 2002; 10 (3): 345-57.

7. Urizzi F, Corrêa AK. Vivências de familiares em terapia intensiva: o outro lado da internação. Rev. latinoam enferm. 2007; 15(4):598-604.

8. Rousso RS, Angelo M. Buscando preservar a integridade da unidade familiar: a família vivendo a experiência de ter um filho na UTI. Rev Esc. 2001.

9. Maslow AH. Motivation and Personality. - New York: Harper \& Brothers, 1954. 411 p.

10. Nascimento ERP, Trentini M. O cuidado de enfermagem na unidade de terapia intensiva (UTI): teoria humanística de Paterson e Zderad. Rev latinoam enferm. 2004; 12(2):250-257.

11. Gimeno A. A família: o desafio da diversidade. Lisboa: Instituto PIAGET, 2001.

12. Alarcão M. (Des) Equilíbrios Familiares. 3a ed. - Coimbra: Editora Quarteto, 2006.

13. Huf DD. A face oculta do cuidar: reflexões sobre a assistência espiritual em enfermagem. - Rio de J aneiro: Mondrian, 2002, 208p.

14. Mohana J. Padres e Bispos Auto-Analisados. Livraria Agir Editora. Rio de Janeiro, 1967.

15. Horta VA. Processo de enfermagem. - São Paulo: EPU: Ed. da Universidade de São Paulo, 1979. $99 \mathrm{p}$.

16. Sluzki CE. A Rede Social na Prática Sistêmica. São Paulo: Casa do Psicólogo, 1997.

17. Boff L. Saber Cuidar: ética do humano - compaixão pela Terra. Petrópolis: Vozes, 1999.

18. Collière MF. Promover a vida: Da Prática das Mulheres de virtude aos cuidados de Enfermagem; Lisboa: Lidel, 1999.

19. Pinheiro ALU, Beuter M, Brondani CM, Roso CC, Flores RG. Humanização no cuidado hospitalar: percepção de familiares acompanhantes. Rev enferm UFSM. 2011;1(2):204-213.

Data de recebimento: $27 / 08 / 2011$

Data de aceite: 01/ 10/2011

Contato com autor responsável: Luzia Wilma Santana da Silva

Endereço postal: Rua Abílio Procópio Ferreira, n³43, Centro, Jequié, BA.

CEP: 45.200-510i

E-mail: luziawilma@gmail.com 